\title{
Puerarin, a selective oestrogen receptor modulator, disrupts pregnancy in rats at pre-implantation stage
}

\author{
Piyali Saha, Ghungroo Saraswat, Pratip Chakraborty ${ }^{1}$, Sayani Banerjee, Bikas C Pal ${ }^{2}$ \\ and Syed N Kabir
}

Department of Reproductive Biology Research, CSIR-Indian Institute of Chemical Biology, Jadavpur, Kolkata 700032, West Bengal, India, ${ }^{1}$ Institute of Reproductive Medicine, Salt Lake, Kolkata 700106, West Bengal, India and

${ }^{2}$ Department of Medicinal Chemistry, CSIR-Indian Institute of Chemical Biology, Jadavpur, Kolkata 700032, West Bengal, India

Correspondence should be addressed to S N Kabir; Email: snkabir@iicb.res.in

P Chakraborty and S Banerjee contributed equally to this work

\begin{abstract}
The tubers of Pueraria tuberosa have folkloric repute as emmenagogue. The n-BuOH fraction of the ethanolic extract of tubers exhibits significant antifertility activity in laboratory animals. The present investigation explored the active principle(s) of the tuber extract with reference to contragestive effects in rats and probed the possible mechanism of action. Bioactivity-guided fractionation identified puerarin as the major constituent that exerted pregnancy-terminating effects. Oral administration of puerarin at $\geq 300 \mathrm{mg} / \mathrm{kg}$ per day for days (D) 1-2 post-coitus resulted in complete implantation failure. Serum oestradiol levels during D2-D5 and progesterone $\left(\mathbf{P}_{4}\right)$ level on D5 remained unaffected, but the endometrial expression of oestrogen receptor $\alpha(E R \alpha)$ and $\operatorname{ER} \beta$ was adversely modulated that disrupted the implantation-specific characteristic endometrial oestrogenic milieu. The eventual consequence was loss of endometrial receptivity characterised by down-regulation of the uterine expression of $\mathbf{P}_{\mathbf{4}}$ receptor $(\mathrm{PR})$ and attenuation of endometrial expression of leukaemia inhibitory factor, vascular endothelial growth factor and cyclo-oxygenase-2, the three important signalling molecules involved in the process of implantation. Light microscopic examination of the embryos demonstrated no untoward effect of puerarin on the development of embryos until D4, but D5 blastocysts underwent gross morphological distortion. The findings taken together are interpreted to suggest that puerarin adversely impacts the uterine expression of ER and PR that disrupts the implantation-conducive uterine milieu and prevents implantation. In conclusion, puerarin may be envisaged as a prospective molecule that merits further exploration for the development of non-steroidal post-coital contraceptive for women.
\end{abstract}

Reproduction (2012) 144 633-645

\section{Introduction}

Unintended pregnancy, abortion and population explosion are the fundamental notions underlying the rationale for contraception (Prata 2009). The available reversible contraceptive options for women fall mainly into the following broad categories: oral contraceptives including emergency contraceptive (EC), implants and injectables; intrauterine devices; barrier methods and non-commodity-based methods (Cullwell \& Curtis 2009). EC, the contraceptive measures that can be taken after sex to prevent pregnancy (Sander et al. 2009), is a popular form of reversible contraception. Oestrogens and progestins, individually or in combination, and antiprogestins form the active constituents of the currently available major hormonal EC formulations (Farrar et al. 2003), but continuous usage of these formulations has undesirable effects that include the proliferative actions of oestrogenic component (Mersereau et al. 2008) or higher failure rate and menstrual abnormalities associated with progestogen-only pills (Ahrendt et al. 2010). Development of a safe and effective non-steroidal contraceptive formulation is therefore recognised as a global need of the day.

The proposed mechanism of ECs may include prevention of ovulation, attenuation of gamete transport and, most likely, blockage of implantation (Kahlenborn et al. 2002). Implantation is a crucial step in the process of establishment of pregnancy, and in rats and mice, it involves participation of oestrogens to a significant extent (Psychoyos 1973). The effects of oestrogens appear to be mediated by two oestrogen receptor subtypes, ER $\alpha$ and ER $\beta$ (Hou et al. 2004). The intriguing biology of oestrogens on different target cells is determined by the structure of the ligand and the ER subtype involved. In many tissues including uterus, 
ER $\alpha$ mediates the proliferative effects, while ER $\beta$ mediates anti-proliferative effects (Marino \& Galluzzo 2008). The process of embryo implantation is $\mathrm{ER} \alpha$ mediated (Achache \& Revel 2006), and the major untoward effects of the oestrogen-based ECs are attributed to their proliferative actions mediated through ER $\alpha$ (Mendez 2002).

Many classes of compounds of plant origin bear future therapeutic promise for the prevention and treatment of many human diseases as well as regulation of fertility (Cravotto et al. 2010). Of particular interest in relation to human health are the class of plant-derived oestrogenlike compounds known as the phyto-oestrogens, which embody several groups of widely distributed nonsteroidal oestrogens including isoflavones and lignans (Cassidy 2003). These phyto-oestrogens modulate ER (Kuiper et al. 1998) and are reported to possess abortifacient activity (Sylvestre et al. 2006).

The tubers of Pueraria tuberosa have folkloric use as emmenagogue (Shukla \& Mathur 2002). Their ethanolic extract and the $\mathrm{n}-\mathrm{BuOH}$ fraction thereof are reported to have significant antifertility activity in rats, mice and hamsters and possess significant oestrogenic activity (Shukla 1996). This communication reports that the major and active constituent of the referred fraction is puerarin, an isoflavone glycoside (Kinjo et al. 1987) that acts as selective oestrogen receptor modulator (SERM; Boue et al. 2003). Boue et al. (2003) demonstrated that puerarin is oestrogenic and exerts preferential agonist activity towards ER $\beta$. We therefore wanted to probe whether puerarin has any prospective anti-implantation properties that may be employed for the development of a post-coital contraceptive lacking the untoward proliferative effects of oestrogens.

\section{Results}

\section{Purification and characterisation of the test compound}

Fractionation and subfractionation of $P$. tuberosa extract yielded subfraction Fr. 2a.1 having antifertility effects. It is composed of three compounds as seen in thin layer chromatography (TLC). The ESI-MS (positive mode) of the pure compound having required activity showed sodiated molecular ion peak $[\mathrm{M}+\mathrm{Na}]^{+}$at $\mathrm{m} / \mathrm{z} 438.96$, in accordance with the molecular formula of $\mathrm{C}_{21} \mathrm{H}_{20} \mathrm{O}_{9}$, which was supported by the ${ }^{13} \mathrm{C}$ NMR spectrum and various DEPT data. 1D and 2D NMR and mass spectral studies identified the active compound as puerarin (Fig. 1), an isoflavone glycoside reported in the literature (Kinjo et al. 1987).

\section{Pilot study and optimisation of dose and duration of treatment}

The administration of puerarin in rats from D1 to D4 resulted in a dose-dependent antifertility effect (Fig. 2A). With an increase in the dose, the percentage of pregnancy failure gradually increased (Fig. 2B, C, D, $\mathrm{E}$ and $\mathrm{F}$ ); at the dose level of $150 \mathrm{mg} / \mathrm{kg}$ body weight $(\mathrm{mg} / \mathrm{kg}) /$ day, the treated rats exhibited complete absence of implantation sites (Fig. 2F).

When treated for D1-D3 and D1-D2, the minimum effective doses (MED) 100 for termination of pregnancy were 200 and $300 \mathrm{mg} / \mathrm{kg}$ per day respectively while single-dose treatment on D1 even up to $500 \mathrm{mg} / \mathrm{kg}$ per day dose level showed no effect on pregnancy. All subsequent studies were performed with $300 \mathrm{mg} / \mathrm{kg}$ per day administered for D1-D2.

\section{Pontamine blue reaction}

As a mark of pontamine sky blue reaction, the control rat uterus exhibited spaced blue reactions with spaced blue spots along the length of both the horns (Fig. 3A); the treated rats did not exhibit any pontamine blue reaction confirming pre-implantation failure (Fig. 3D).

\section{Effect on histoarchitecture of uterus and ovary}

Histological sections of the D5 control rat uterus showed characteristic secretory endometrium with slit-like narrow lumen (Fig. 3B). The stromal cells were modified to large round, oval or polygonal decidual cells; uterine glands were tortuous and implantation chambers with blastocyst were visible (Fig. $3 \mathrm{~B}_{1}$ ). In sharp contrast, the histoarchitecture of the endometrium in the treated rat showed oestrogenic influence as evidenced by proliferated luminal epithelial lining (Fig. $3 \mathrm{C}$ and $\mathrm{C}_{1}$ ). Structures of both control (Fig. 4A) and treated (Fig. 4B) ovaries demonstrated the presence of corpora lutea $(\mathrm{CL})$ characterised by well-outlined lutein cells (Fig. $4 \mathrm{~A}_{1}$ and $\mathrm{B}_{1}$ ) and indicated that $\mathrm{CL}$ were functional.

\section{Effect on serum oestradiol and progesterone levels}

Serum oestradiol $\left(E_{2}\right)$ levels during D2-D5 did not differ between the control and treated groups (Fig. 5).

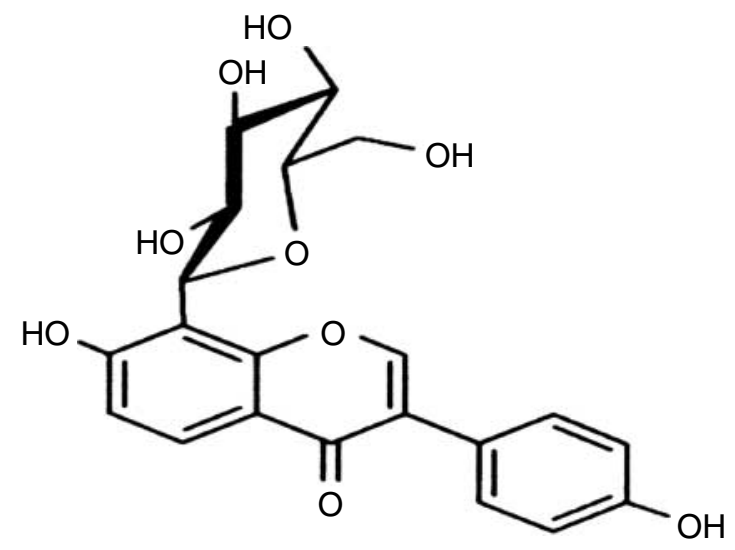

Figure 1 Structure of puerarin. 

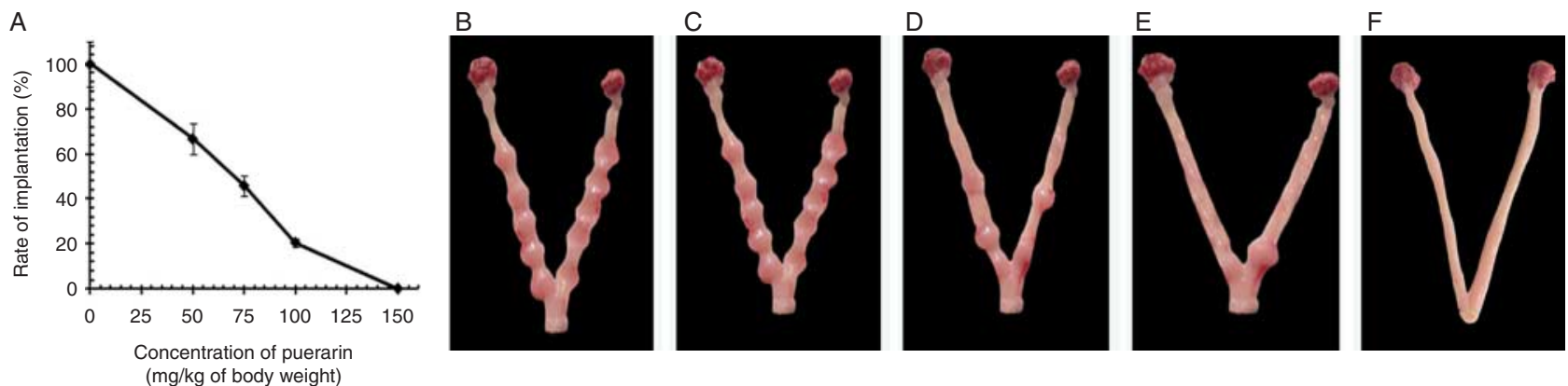

Figure 2 Dose-dependent antifertility outcomes of pilot study as evaluated by the uterine presence/absence of implantation sites. Pregnant rats were orally administered with vehicle (control) or puerarin at different dose levels for D1-D4 of pregnancy and laparotomised on D10, when the uteri were examined for the presence of embryo. (A) Depicts the dose vs antifertility response to puerarin. Each datum point on $X$-axis represents the mean \pm s.E.M. of implantation rate (\%) of six to eight rats. Fertility rate $=(($ number of sites/number of corpus luteum) $\times 100)$. (B, C, D, E and F) Show photographs of implantation swellings of D10 uteri of rats treated with vehicle (B), or puerarin at $50 \mathrm{mg} / \mathrm{kg}$ per day (C), $75 \mathrm{mg} / \mathrm{kg}$ per day (D), $100 \mathrm{mg} / \mathrm{kg}$ per day (E) and $150 \mathrm{mg} / \mathrm{kg}$ per day (F) dose levels.

The D5 serum progesterone $\left(\mathrm{P}_{4}\right)$ levels $(\mathrm{ng} / \mathrm{ml})$ were statistically comparable between the control (110.89 $\pm 0.23)$ and treated $(100.67 \pm 0.96)$ groups.

\section{Effect on embryos}

Light microscopic examination apparently revealed no difference between the embryos retrieved during D2-D4 from the oviduct of the puerarin-treated (Fig. 6B, D and F) and control groups (Fig. 6A, C and E). However, compared with the control D5 blastocysts (Fig. 6G) that were differentiated distinctly into trophectoderm and inner cell mass, the puerarin-exposed blastocysts (Fig. 6H) appeared as lumps of cells implying morphological distortion.
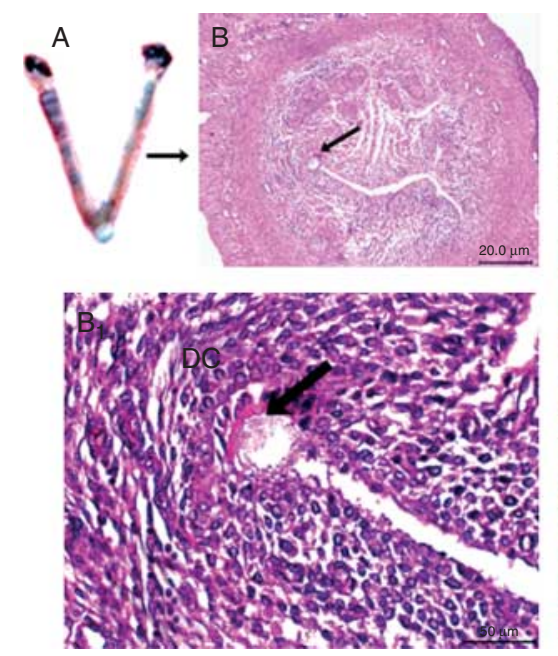

\section{Effects on uterine expression of leukaemia inhibitory factor, COX2 and vascular endothelial growth factor}

Immunofluorescence analyses of uterine leukaemia inhibitory factor (LIF), cyclo-oxygenase-2 ((PTGS2) COX2) and vascular endothelial growth factor (VEGF) on D5 are presented in Fig. 7. In the control rats (Fig. $7 \mathrm{~A}_{1}, \mathrm{~A}_{2}, \mathrm{~A}_{3}$ and $\mathrm{A}_{4}$ ), uterine LIF was highly expressed in the epithelial lining of the lumen. The puerarin-treated rat uteri (Fig. $7 \mathrm{~B}_{1}, \mathrm{~B}_{2}, \mathrm{~B}_{3}$ and $\mathrm{B}_{4}$ ), by contrast, demonstrated no expression of LIF.

Compared with higher expression of PTGS2 in the luminal epithelia and stroma surrounding the site of blastocyst attachment at the anti-mesometrial side of control uterus (Fig. $7 \mathrm{C}_{1}, \mathrm{C}_{2}, \mathrm{C}_{3}$ and $\mathrm{C}_{4}$ ), the

Figure 3 Anti-implantation activity of puerarin as evaluated by pontamine sky blue reaction ( $\mathrm{A}$ and $\mathrm{D})$ and uterine histoarchitecture at lower $(\mathrm{B}$ and $\mathrm{C}$ ) and higher magnification $\left(B_{1}\right.$ and $C_{1}$ ) on D5. Pregnant rats were administered with vehicle (control) or puerarin at $300 \mathrm{mg} / \mathrm{kg}$ per day for D1 and D2. On day 5 at $1800 \mathrm{~h}$, five to seven rats in each group received injection of $0.3 \mathrm{ml}$ of $1 \%$ pontamine sky blue solution through tail vein and killed after $30 \mathrm{~min}$, when pontamine blue reaction was observed and uterine horns were dissected out for histological staining with haematoxylin-eosin. The representative control uterine horn (A) exhibits positive blue reaction with spaced blue spots along the length of the both uterine horns, while the treated uterus (D) demonstrates no such reaction. Uterine cross section of control rat shows the presence of probably an embryo within the implantation chamber (arrow) with secretory phenotype of the endometrium ( $B$ and $\left.B_{1}\right)$, but the treated rat uterus $\left(C\right.$ and $\left.C_{1}\right)$ features proliferative phenotype. Each image is one representative of several ovarian sections from six to eight rats. DC, decidual cell; PLE, proliferative luminal epithelia. 

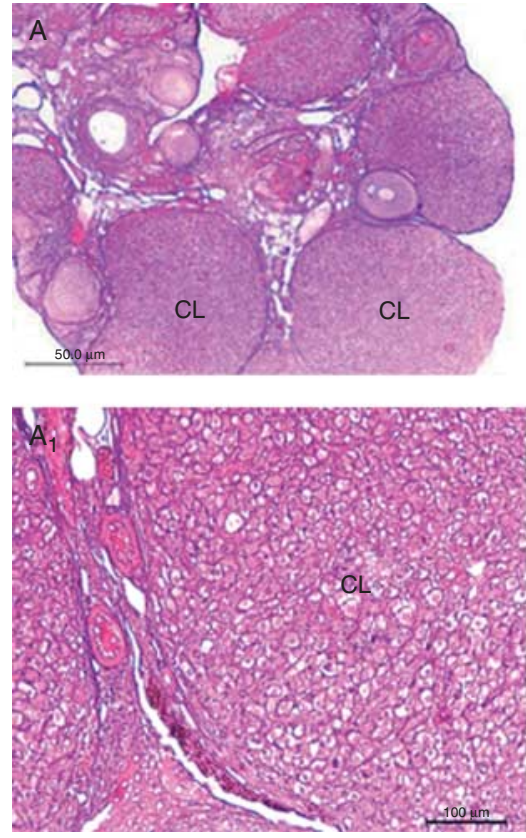
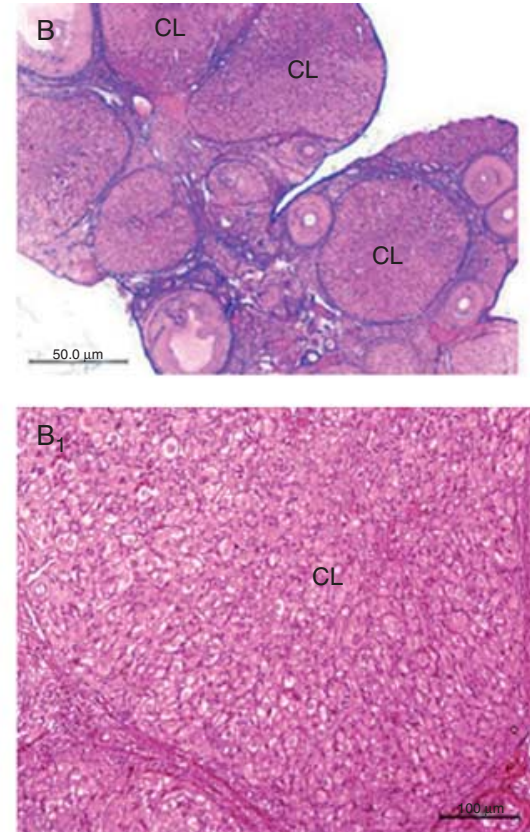

Figure 4 Effect of puerarin on ovary. Images show histoarchitecture of D5 vehicle-treated control (A) and puerarin-treated $(300 \mathrm{mg} / \mathrm{kg}$ per day for D1 and D2) (B) rat ovaries. Haematoxylin-eosinstained ovarian sections of both control and puerarin-treated rats show the presence of $\mathrm{CL}$ composed of well-outlined and compact lutein cells $\left(A_{1}\right.$ and $\left.B_{1}\right)$ that characterize functional $C L$. Each image is one representative of several ovarian sections from six to eight rats. puerarin-treated rat uterus exhibited little or no signalling for COX2 (Fig. 7D $, D_{2}, D_{3}$ and $D_{4}$ ).

The control rat uterus demonstrated intense signalling for VEGF both at luminal and at glandular epithelia (Fig. $7 \mathrm{E}_{1}, \mathrm{E}_{2}, \mathrm{E}_{3}$ and $\mathrm{E}_{4}$ ), while the study group (Fig. $7 \mathrm{~F}_{1}$, $F_{2}, F_{3}$ and $F_{4}$ ) exhibited no discrete signalling.

\section{Uterine expression of uterine $E R \alpha, E R \beta, P R B$ and $P R A B$}

The real-time PCR data on the uterine expression of candidate mRNAs in the control and treated groups during D3-D5 are presented in Fig. 8A and B. Neither of the groups demonstrated appreciable expression of PRB during the days of study (the results are not shown in the figure). But there was gross alteration in the expression profile of $E R \alpha, E R \beta$ and $P R A B$ mRNAs in the study population. Figure $8 \mathrm{~A}$ represents day-wise changes in the expression levels of the candidate mRNAs in the individual groups with respect to the D3 levels of corresponding group. In the control group, the D4 endometrial expression of $E R \alpha$ increased significantly over that of D3 $(P<0.05)$ and showed no further change on $\mathrm{D} 5$, while $E R \beta$ expression remained very low and statistically indifferent through D3-D5. The study population, by contrast, demonstrated no changes in $E R \alpha$ expression levels during D3-D5, but ER $\beta$ levels increased significantly from D3 to D5 $(P<0.05)$. As a result, $\mathrm{ER} \alpha: \mathrm{ER} \beta$ ratio on $\mathrm{D} 4$ and $\mathrm{D} 5$, relative to $\mathrm{D} 3$ of the corresponding groups, was significantly $(P<0.05)$ higher in the control group and lower in the study group. The change in the expression pattern of PRAB accorded with that of ER $\alpha$. With respect to D3, the expression of $P R A B$ on D4 and D5 increased $(P<0.05)$ gradually in the control group but decreased $(P<0.05)$ gradually in the treated group.

The day-specific expression pattern of receptor mRNAs in the study group with respect to the corresponding day of the control group is presented in Fig. 8B. The D3 expression levels of none of the receptors differed significantly between the groups. During the subsequent days, however, the treated group had significantly $(P<0.05)$ higher expression of $E R \beta$

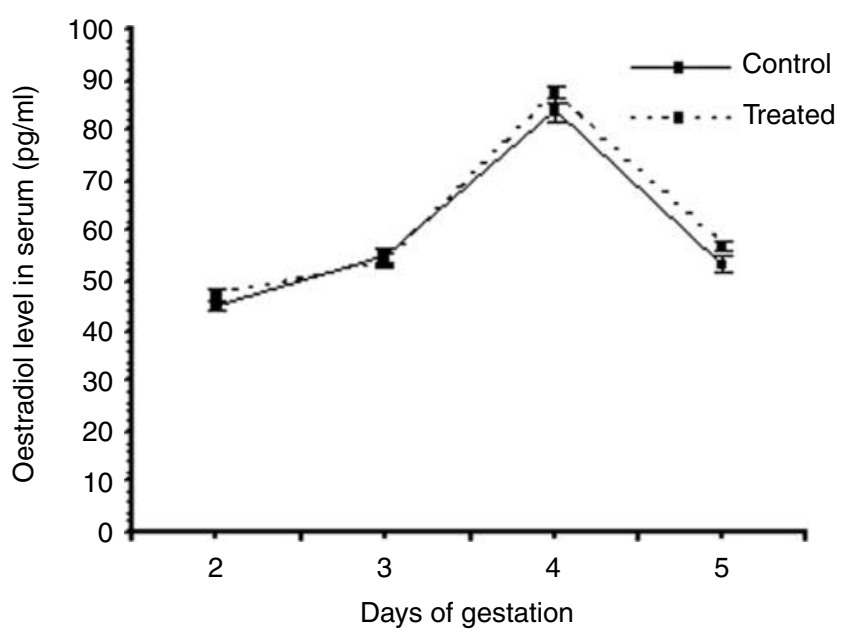

Figure 5 Day-wise serum $\mathrm{E}_{2}$ levels ( $\mathrm{pg} / \mathrm{ml}$ ) between D2 and D5. In both the vehicle-treated control and puerarin-treated $(300 \mathrm{mg} / \mathrm{kg}$ per day for D1-D2) groups, the D4 $\mathrm{E}_{2}$ levels rise significantly $(P<0.05)$ over the respective D2/3 levels, followed by sharp decline (D4 vs D5: $P<0.05$ ) on D5. Day-wise there are no differences in the $E_{2}$ levels between the groups. Each datum point on $X$-axis represents the mean \pm S.E.M. of $E_{2}$ levels of seven rats. 

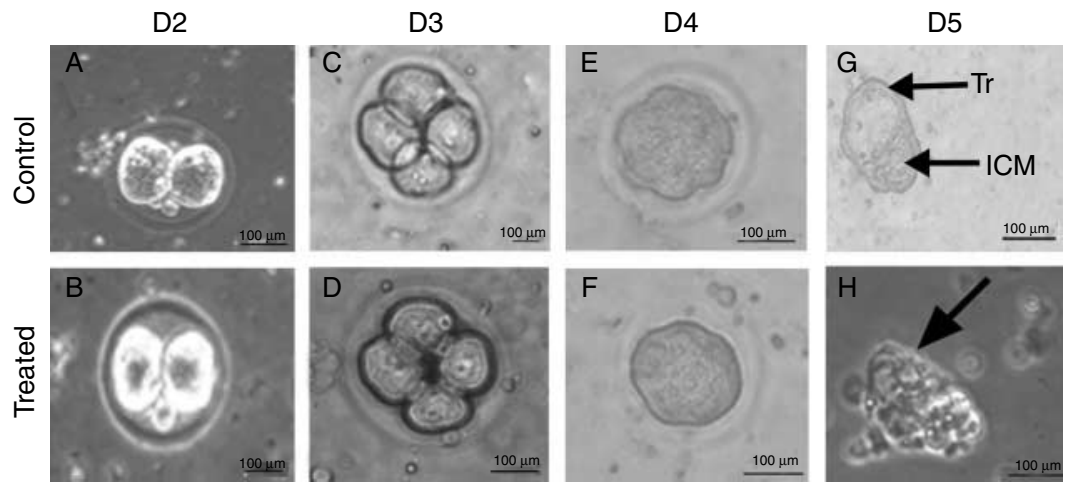

Figure 6 Light microscopic images of pre-implantation embryos. Embryos were retrieved from control and puerarin-treated (300 mg/kg per day for D1-D2) rats by flushing the oviducts/uterine horns between D2 and D5. No visible changes are apparent between the control and treated embryos during D2-D4 (A, B, C, D, E and F), while compared with the D5 control blastocysts (G) that are well differentiated into inner cell mass (ICM) and trophectoderm $(\mathrm{Tr})$, the puerarin-treated blastocysts $(\mathrm{H})$ are grossly distorted that appears as a lump of cells (arrow). Each embryo is one representative of several images of the respective group.

(D4: 1.38-fold; D5: 1.7-fold) and lower levels of ER $\alpha$ (D4: 0.59-fold; D5: 0.53-fold), ER $\alpha: E R \beta$ (D4: 0.43-fold; D5: 0.31-fold), and PRAB (D4: 0.26-fold; D5: 0.11-fold).

\section{Discussion}

The butanolic fraction of $P$. tuberosa is reported to possess oestrogenic property and exert antifertility activity (Shukla 1996). This study demonstrates that the referred fraction is composed mainly of three compounds: the major one that represents $90.69 \%$ (by high-performance liquid chromatography) of the total mass is the most active one with respect to termination of pregnancy and identified as puerarin, an isoflavone glycoside reported in the literature (Kinjo et al. 1987).

Puerarin is a polyphenolic non-steroidal plant-derived compound with oestrogen-like biological activity, i.e. a phyto-oestrogen (Hwang \& Jeong 2008). In the present investigation, a pilot study followed by dose-duration optimisation study demonstrates that oral administration of puerarin at $300 \mathrm{mg} / \mathrm{kg}$ for D1-D2 is the minimum effective regimen that disrupts pregnancy completely.

Based on the timing of implantation, the gestation period in rats may be broadly segregated under preimplantation and post-implantation phases. In rats, the blastocysts get implanted on day 5 of pregnancy (Psychoyos 1984). In order to find out whether the pregnancy-terminating effect of puerarin is due to failure of implantation, or is executed during the early postimplantation phase, we performed uterine pontamine blue reaction. The endometrium is normally a nonreceptive environment for an embryo, except during a short implantation window during which it becomes optimally receptive to an implantation-competent blastocyst (Tabibzadeh 1998). The earliest known response of a receptive endometrium to the physical contact of blastocysts is localised increase in endometrial vascular permeability at the site of blastocyst apposition (Matsumoto et al. 2002). This vascular response can be identified by i.v. injection of a macromolecular colorant like pontamine blue that leaves the circulation at the hyperpermeable regions and gets deposited to produce discrete spots at precisely the anticipated sites of implantation, where the blastocysts are in apposition to the luminal epithelium (Psychoyos et al. 1995). In sharp contrast to that of the control rats that exhibited discrete blue spots along the length of the uterine horn, no bluing reaction was evidenced in the study group. This observation suggests that puerarin perhaps executes its action in the pre-implantation period. This proposition is further supported by the observation that compared with the characteristic secretory type of endometrial histoarchitecture of the D5 control pregnant rat uteri, the treated rats exhibited oestrogen-dominated proliferative features. This observation was not surprising in the light of the established oestrogenic properties of puerarin (Zheng et al. 2002, Boue et al. 2003).

Implantation is the result of reciprocal interaction between the implantation-competent blastocyst and receptive uterus (Hamatani et al. 2004). The uterus differentiates into an altered state when blastocysts are capable of mediating effective two-way communication to initiate the process of implantation (Dey et al. 2004). The major hormones that specify uterine receptivity are the ovarian steroids $\mathrm{P}_{4}$ and oestrogen (Simon et al. 2003). $\mathrm{P}_{4}$ is essential for implantation and pregnancy maintenance in all mammalian species, while the requirement for ovarian oestrogen is species specific. In mice and rats, however, both oestrogen and $\mathrm{P}_{4}$ are an absolute requirement for implantation to occur (Wang \& Dey 2006). In these species, pre-ovulatory ovarian oestrogen secretion causes proliferation and differentiation of the luminal and glandular epithelia during the first 2 days of pregnancy, while rising $\mathrm{P}_{4}$ levels elaborated by the newly formed CL superimposed on the pre-ovulatory oestrogen surge shifts the proliferation and differentiation from epithelia to the stroma and induces secretory type of changes. These effects are further potentiated by a 

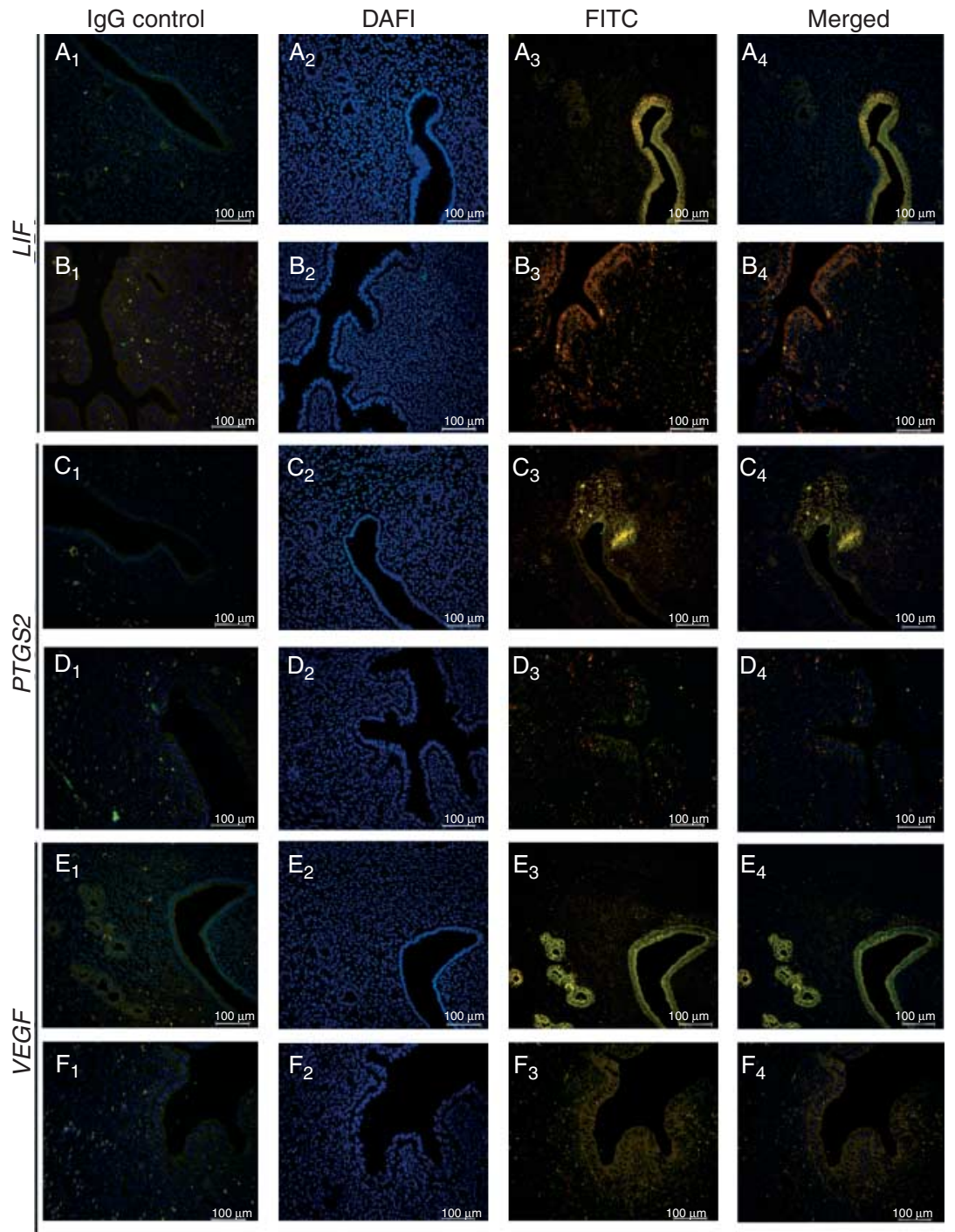
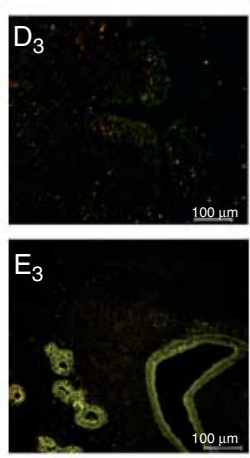

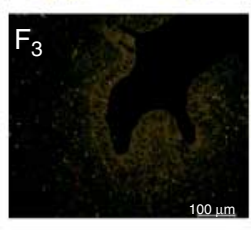

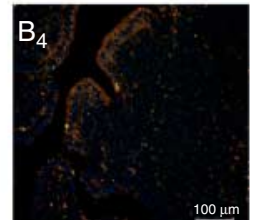
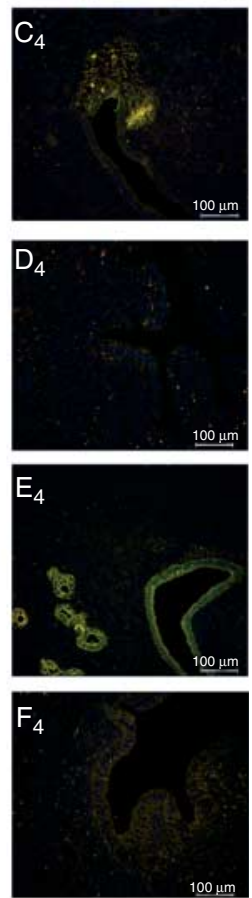

Figure 7 Effect of puerarin on the uterine expression of LIF, PTGS2 and VEGF. The overlaid immunofluorescence images viewed under fluorescence microscope represent D5 control and puerarintreated (300 mg/kg per day for D1-D2) rat uterus analysed for the expression of LIF, PTGS2 and VEGF using respective antibodies conjugated to FITC. The yellowish green deposits indicate the sites of positive staining. Negative control was run by replacing the specific primary antibodies with respective normal $\operatorname{lgG}$. The left-hand column of pictures represents IgG control for the corresponding row of sections that demonstrate no specific staining. In the control rats $\left(A_{1}, A_{2}, A_{3}\right.$ and $\left.A_{4}\right)$, LIF is expressed along the entire luminal epithelia; however, there is absence of such signal in the treated group $\left(\mathrm{B}_{1}, \mathrm{~B}_{2}, \mathrm{~B}_{3}\right.$ and $\left.\mathrm{B}_{4}\right)$. PTGS2 is expressed in the epithelial cells and uterine stroma surrounding the site of blastocyst attachment in the control rats $\left(\mathrm{C}_{1}, \mathrm{C}_{2}, \mathrm{C}_{3}\right.$ and $\left.\mathrm{C}_{4}\right)$, while the treated rat uteri show no appreciable expression $\left(D_{1}, D_{2}, D_{3}\right.$ and $\mathrm{D}_{4}$ ). Expression of VEGF in the control rat uterine sections $\left(E_{1}, E_{2}, E_{3}\right.$ and $\left.E_{4}\right)$ is observed in the luminal and glandular epithelia throughout the endometrium, but the treated group fails to show such expression $\left(F_{1}, F_{2}, F_{3}\right.$ and $\left.F_{4}\right)$. Each image is one representative of four to five replicates of the concerned group. pre-implantation D4 ovarian secretion of $E_{2}$, which also necessarily increases endometrial capillary permeability at the location of blastocyst and subsequently transforms stromal cells to decidual cells in the presence of the blastocyst (Dey 1996). In rats, CL of oestrus cycles are ephemerally active structures that secrete sufficient $\mathrm{P}_{4}$ only for a brief period shortly after ovulation (Keyes \& Wiltbank 1988). But in pregnancy or pseudopregnancy, the coital act stimulates release of sufficient quantity of pituitary prolactin that rescues the $\mathrm{CL}$ and allows them to persist until D 11/12 when placenta takes over (Terkel 1988). Maintenance of CL production and peripheral level of $\mathrm{P}_{4}$ until the establishment of placental physiology is independent of the presence of embryo (McCracken et al. 1999). In this study, observation of unaltered serum $E_{2}$ levels during D2-D5 and serum $\mathrm{P}_{4}$ on D5 discounts the possibility of deficient ovarian production of $E_{2}$ and $P_{4}$ as the mechanism of puerarin action. But to our surprise, despite unhindered
$\mathrm{P}_{4}$ production, the endometrium lacked secretory phenotype.

Uterine sensitivity with respect to steroid hormonal requirement involves exposure to a small amount of oestrogen after $\mathrm{P}_{4}$ priming (Dey et al. 2004). In rats, the uterus is most receptive on the day of implantation (Dey et al. 2004). Recent evidence suggests that concentration of oestrogen within a very narrow range determines the duration of the window of receptivity. It rapidly closes at higher levels of oestrogen that induce aberrant expression of implantation-related genes and totally prevent expression of $\mathrm{P}_{4}$ receptor (Dey et al. 2004). This raises the possibility that the oestrogenic potential of puerarin perhaps overshoots the threshold limit of uterine oestrogenic milieu that is conducive to implantation, and the endometrium displays no secretory phenotype because of attenuated PR synthesis.

The actions of $\mathrm{P}_{4}$ are primarily mediated via binding to specific nuclear receptors in the target cells. PR exists in 

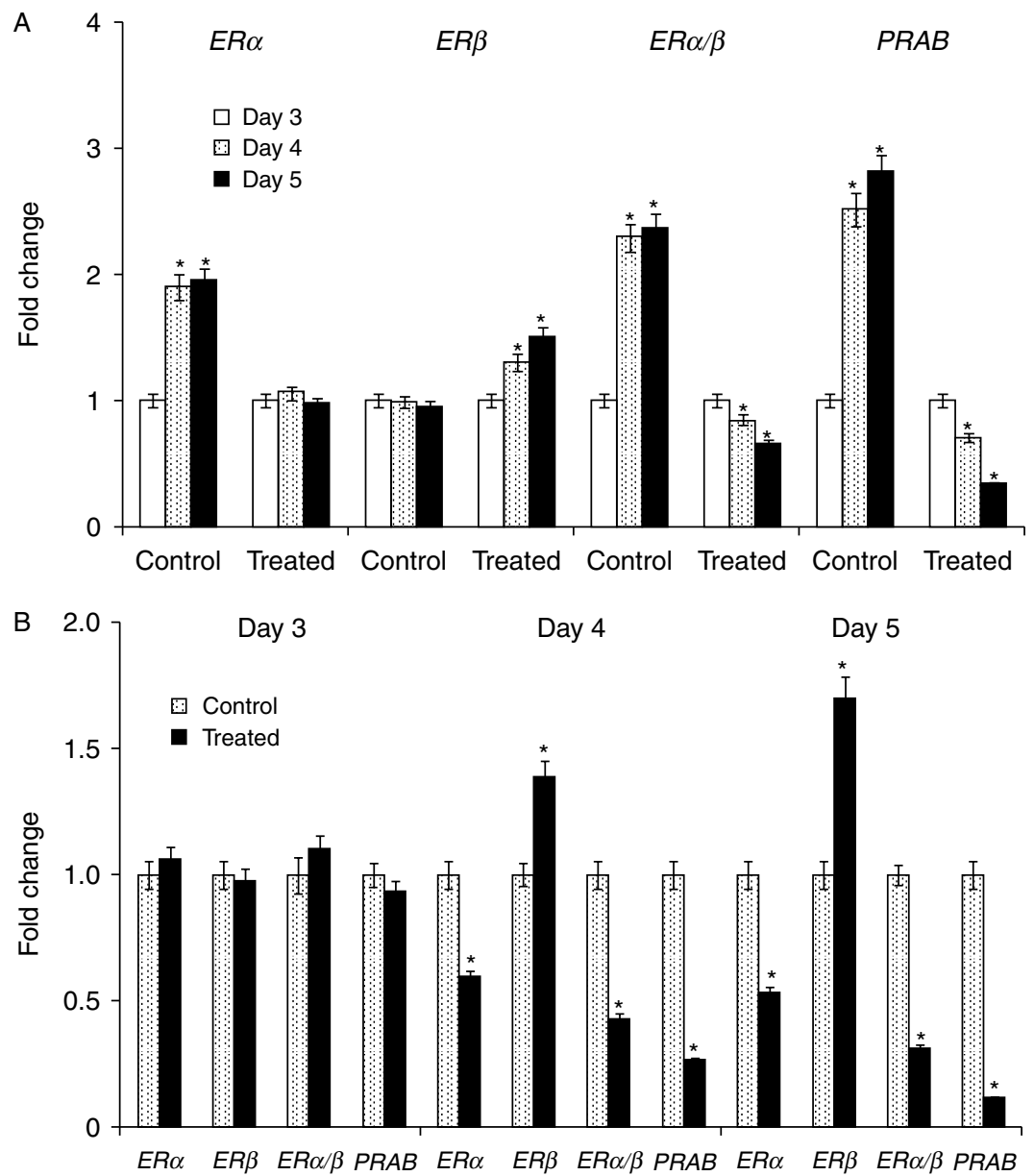

Figure 8 Real-time RT-PCR data on mRNA levels of $E R \alpha, E R \beta$ and $P R A B$ in rat uterus during D3-D5. Pregnant rats were administered with vehicle (control) or puerarin at $300 \mathrm{mg} / \mathrm{kg}$ per day for D1 and D2 of pregnancy. Total RNA was extracted from uterus dissected out at $1600 \mathrm{~h}$ on each day between D3 and D5. RNA (5 $\mu \mathrm{g})$ was reverse transcribed to synthesize single-stranded cDNA and amplified using specific primers in 'PCR reagent system'. The mRNA levels were first normalized to that of a housekeeping gene GAPDH and further calculated by the $2^{-\Delta \Delta \mathrm{Ct}}$ method. (A) The daywise changes in the uterine expression of $E R \alpha, E R \beta$ and $P R A B \mathrm{mRNAs}$, and $E R \alpha: E R \beta$ in the control and treated groups are represented as fold change vs D3 of the corresponding group, which was arbitrarily assigned value 1. ER $\alpha$ expression on D4 and D5 increases significantly over that of D3 in the control group, while the treated group demonstrates no change in the expression levels during these days. $E R \beta$ expression in the control group shows no variation during D3-D5; the treated group, by contrast, shows gradual increase in D4 and D5 over that of D3. The control group exhibits significantly increased $E R \alpha / \beta$ ratio on D4 and D5 but the treated group shows significantly lower ratio on D4 and D5, relative to D3. The expression of $P R A B$ on D4 and D5, with respect to D3, gradually increases in the control group but decreases in the treated group. (B) The day-specific expression pattern of receptor mRNAs in the study group is presented as fold change with respect to the corresponding day of the control group with arbitrarily assigned value 1. Expressions of $E R \alpha, E R \beta$ and $P R A B \mathrm{mRNA}$ on D3 are not different between the groups. However, relative to the respective controls, expression of $E R \alpha$ decreases while $E R \beta$ increases significantly on D4 and D5. $E R \alpha: E R \beta$ and $P R A B$ mRNA levels also show significant decrease on D4 and D5 compared with that of respective controls. Values represent the mean \pm s.E.M. of three individual experiments. Figure bars with asterisk vary significantly $(P<0.05)$.

two major isoforms, $\mathrm{A}(\mathrm{PRA})$ and $\mathrm{B}(\mathrm{PRB})$, that arise due to use of different promoters (Misrahi et al. 1988), and expression of PR is primarily regulated post-translationally and/or translationally (Murata \& Higuchi 2003). The essential $\mathrm{P}_{4}$-regulated functions including implantation are primarily mediated by PRA (Wang \& Dey 2006), but PRA is basically very difficult to detect (Sahlin et al. 2006). In order to examine the effects of puerarin on PR expression during the pre-implantation phase, we used oligonucleotide primer for PRAB and PRB, but the expression of the latter was not detectable. As uterine PRB is faintly expressed in early pregnant rats (Sahlin et al. 2006), the expression of $P R A B$ primarily represents PRA. Of importance to note that compared with controls, there was significant decrease in $P R A B$ expression during the window of implantation (day 5). This perhaps explains the lack of secretory endometrial phenotype despite unaltered $\mathrm{P}_{4}$ levels.

The diverse actions of oestrogens involve ERdependent and -independent signalling pathways, but 
evidence suggests that oestrogen-mediated uterine events for implantation are primarily mediated via nuclear receptors. Oestrogen mediates its effects by two ER subtypes, ER $\alpha$ and ER $\beta$ (Hou et al. 2004). The mRNA of the two ER subtypes coexists in the rat uterus during pregnancy (Minorics et al. 2004), but the process of embryo implantation possibly involves $E R \alpha$-mediated endometrial effects (Ma et al. 2003). No information is available on the precise role of ER $\beta$; perhaps it functions as a transdominant inhibitor of $E R \alpha$ transcriptional activity (Kuiper et al. 1998). Earlier workers demonstrated appreciable expression of $\operatorname{Er} \beta$ mRNA in pregnant rat uterus from D7 onwards (Minorics et al. 2004). In this study, the control group exhibited a characteristic increase in endometrial Er $\alpha$ mRNA expression on D4 and D5 over that of D3, when Er $\beta$ mRNA was poorly expressed. In the study population, by contrast, there was a significant increase in $E r \beta$ expression on D4 and D5 accompanied by no change in the Er $\alpha$ expression that ultimately led to significant decrease in the ratio of $E R \alpha$ to $E R \beta$, as opposite to its increase in the control rats. Our real-time PCR data demonstrated that compared with respective day-wise control, the expression of Er $\alpha$ significantly decreased while that of $\operatorname{Er} \beta$ increased on D4 and D5.

It may be relevant in this context that the ratio of ER $\alpha$ to $E R \beta$ at target site may be an important determinant of the overall action of oestrogen or SERM (Jordan 2007). The uterine $P R$ expression is mostly regulated by ovarian steroids: $E_{2}$ acting via $E R \alpha$ increases, whereas ER $\beta$ agonists decrease the mRNA expression of PRAB. Thus the decreased $E R \alpha$ to $E R \beta$ ratio that characterised ER profile in the puerarin-treated rats explains down-regulation of $P R A B$ expression and consequent $\mathrm{P}_{4}$-deficient feature of endometrium, although the serum $\mathrm{P}_{4}$ levels were optimum. It therefore appears that adverse alteration of endometrial ER subtypes may be central to the anti-implantation effects of puerarin.

The mechanism by which oestrogen prepares the uterus to the receptive state is not yet clearly defined. A broad variety of cytokines, growth factors, homeobox transcription factors and COX-derived prostaglandin (PG) participate in the process through autocrine, paracrine and/or juxtacrine mechanism (Dey et al. 2004). In this study, we investigated the effects of puerarin on LIF, COX2 and VEGF - the three important factors actively associated with implantation process.

In a number of mammalian species, uterine expression of LIF and its receptors coincide with blastocyst implantation. The principal function of LIF may be to regulate blastocyst growth and implantation. LIF plays dual roles in implantation: a critical role in uterine preparation initially and in attachment reaction later (Dey et al. 2004). We observed that in the control rats, D5 uterine LIF was expressed in the epithelial lining surrounding the lumen. The puerarin-treated rats, by contrast, demonstrated no expression of LIF. This may perhaps be a major, if not the sole, factor inhibiting implantation. This contention goes well with the earlier report that a highly potent LIF antagonist is $100 \%$ effective in blocking implantation (White et al. 2007).

Other important downstream regulators of implantation include COX2 and VEGF that were significantly down-regulated in the puerarin-treated rat uterus. Recent evidence demonstrates that PTGS2 expression during attachment reaction is critical to implantation (Chakraborty et al. 1996). It is expressed in the uterus, blastocyst or both in a variety of species, and COX2 in turn up-regulates PG, primarily prostacyclin, that induces VEGF needed for vascular permeability and angiogenesis during implantation (Matsumoto et al. 2002, Dey et al. 2004). However, the onset of this chain of events is subject to the presence of active blastocyst, which is an absolute requirement for the induction of COX2 (Song et al. 2000). Our observation that down-regulated expression of PTGS2 and VEGF in the puerarin-treated rats in parallel with the morphological distortion of blastocysts raises the possibility if puerarin primarily exerted direct blastotoxic effect, while the rest are secondary to the absence of active blastocyst.

The knowledge on pre-implantation embryo development is as yet incomplete but it is known that oocyte is programmed before fertilisation to undergo the earliest stages of its embryonic development. In rats and mice, neither oestrogen- $\mathrm{P}_{4}$ (Sengupta et al. 1983) nor LIF (Ware et al. 1995) is critical for embryo development until blastocyst formation, but if the blastocysts do not get implanted due to absence of or erratic oestrogen effects, the embryo needs continued $\mathrm{P}_{4}$ support for its survival in utero until a small amount of oestrogen is applied that can render the endometrium receptive and induce implantation (Dey 1996). So, uncompromised embryo development until D4 followed by distortion of blastocyst on D5 coupled with $\mathrm{P}_{4}$ deficiency at the endometrial level due to down-regulated endometrial PR implies that perhaps loss of blastocyst competency was not direct, rather a secondary effect to withdrawal of $\mathrm{P}_{4}$ support.

Taken together, the present findings demonstrate that administration of puerarin immediately after mating down-regulates a number of crucial implantationmediating factors and thus adversely impacts the endometrial effects of oestrogen to prevent implantation. The precise mechanism of action needs to be further explored; however, oestrogenic potential of puerarin perhaps can provide a little explanation in this respect. As referred in the preceding section, oestrogen-regulated expression of implantation-specific genes encoding LIF and PTGS2 and induction of uterine receptivity are precisely dependent on dose of oestrogens (Ma et al. 2003). It was critically demonstrated that Lif and Ptgs2 expressions are correctly induced by low concentration 
of $E_{2}$, while higher doses inhibited the expression and prevented implantation. Serum levels of $E_{2}$ during D2-D5 were not affected, but puerarin has estrogenic effects at the level of uterus. It therefore appears reasonable to speculate that oestrogenic potential of puerarin disrupted the so-called critical uterine oestrogenic milieu and induced aberrant expression of the concerned implantation-specific factors.

The currently available ECs are mostly steroid based and therefore not devoid of steroidogenic side effects (Kahlenborn et al. 2002, Ahrendt et al. 2010). Puerarin may be projected as a prospective contraceptive molecule that can be further explored for the development of non-steroidal emergency/post-coital contraceptive. One major limitation in this direction appears to be its high $\mathrm{MED}_{100}$ in rats. Pharmacological studies, however, demonstrate that MED of a drug in humans is almost $1 / 7$ th of that in rats (Bitto et al. 2009). It is also important to note that the bioavailability of puerarin in vivo is often limited by its insolubility. A recent report documents that enzymatic modification of puerarin to puerarin glycoside increases the solubility $>100$-fold (Chung et al. 2009); however, it remains to be ascertained if the pregnancy-terminating potential of puerarin is retained by its glycosidic form. Moreover, puerarin nanoparticles are reported to have good stability, enhanced intestinal absorption and increased bioavailability after oral administration (Liu et al. 2009, Wu et al. 2009). So, puerarin glycoside nanoparticles may be explored in this respect.

There has also been concern with respect to adverse effects of some isoflavones on reproductive and developmental functions (Wuttke et al. 2010). But a recent report on toxicological evaluation in rats demonstrates that puerarin and its glycosides are not mutagenic, rather they exert anti-mutagenic effects and do not have significant toxic effects at doses of up to $250 \mathrm{mg} / \mathrm{kg}$ per day for 28 days (Chung et al. 2009). The high MED of puerarin in rats, therefore, should not be a major strategic constraint in exploring its future potential as antifertility agent. Moreover, puerarin and puerarincontaining plants have many therapeutic applications in traditional medicine (Chung et al. 2009), which suggests that this drug is not unacceptably toxic. The present findings, however, raise the issue if therapeutic uses of puerarin are contraindicated in pregnancy.

In summary, puerarin is an SERM that terminates pregnancy in rats at a very early stage. Its mode of action possibly involves adverse modification of the uterine expression of ER subtypes and consequent down-regulation of PR that disrupts the implantationconducive uterine milieu and prevents implantation. We conclude that puerarin is perhaps a prospective candidate molecule that may be further explored for future development of non-steroidal emergency or postcoital contraceptives.

\section{Materials and Methods}

\section{Chemicals}

Unless otherwise stated, chemicals used for the preparation of reagents were of analytical grade and purchased from SigmaAldrich Co. Goat polyclonal LIF (sc-48575) antibody, rabbit polyclonal VEGF (sc-507), goat polyclonal COX2 (sc-1745) antibody, goat IgG (sc-2028), rabbit IgG (sc-2027), mouse antigoat IgG secondary antibody-FITC (sc-2356), and goat antirabbit IgG secondary antibody-FITC (sc-2012) were obtained from Santa Cruz Biotechnology, Santa Cruz, CA, USA. M2 medium (AL-142) was purchased from Himedia (Mumbai, India). All other common chemicals including methanol $(\mathrm{MeOH})$, chloroform $\left(\mathrm{CHCl}_{3}\right), 2$-amino-2-(hydroxymethyl)1,3-propanediol hydrochloride (Tris. $\mathrm{HCl}$ ), sucrose, ethylene glycol tetraacetic acid, $\mathrm{KCl}, \mathrm{MgCl}_{2}$, dithiothreitol (DTT) and picric acid were obtained from Merck Specialities Pvt Ltd.

\section{Animals}

Adult healthy female and male Sprague Dawley rats (Rattus norvegicus, 180-220 g) were housed in controlled conditions of room temperature $\left(23 \pm 2{ }^{\circ} \mathrm{C}\right)$, humidity $(50 \pm 5 \%)$ and a $12 \mathrm{~h}$ light:12 h darkness cycle. The animals were kept in sanitised polypropylene cages and were fed with standard rat pellet diet and drinking water ad libitum. All experiments were performed as per the national guidelines formulated by the Committee for the Purpose of Control and Supervision of Experiments on Animals, Ministry of Culture, India, with approval from the Animal Ethics Committee of Indian Institute of Chemical Biology.

\section{Plant materials}

Tubers of $P$. tuberosa were supplied by United Chemicals Ltd., Kolkata, India, who maintain a voucher specimen at their herbarium. Dr N D Paria, Department of Botany, University of Calcutta, identified the plant material.

\section{Purification and characterisation of compound}

Air-dried tubers of $P$. tuberosa $(1 \mathrm{~kg})$ were extracted with $\mathrm{MeOH}: \mathrm{H}_{2} \mathrm{O}:: 1: 1$ at room temperature for 7 days; the process was repeated three times. The solvent was evaporated to dryness in vacuo. The residue (90 g) was suspended in water $(500 \mathrm{ml})$ and extracted with EtOAc to remove the less polar parts. Finally, it was extracted with $\mathrm{n}-\mathrm{BuOH}(3 \times 500 \mathrm{ml})$. A part (14 g) of the $\mathrm{n}-\mathrm{BuOH}$ extract was subjected to Diaion HP-20 chromatography using a running gradient of $50-100 \%$ $\mathrm{MeOH}: \mathrm{H}_{2} \mathrm{O}$. The $\mathrm{MeOH}: \mathrm{H}_{2} \mathrm{O}:: 1: 1$ eluate was subdivided into two crude fractions (saponin fraction: Fr. $1 \mathrm{a} ; 8.2 \mathrm{~g}$ and isoflavone fraction: Fr. 2a; $4.3 \mathrm{~g}$ ) by TLC monitoring. Both the fractions were tested for antifertility activity. Fr. 2a, which showed the required activity, was subjected to column chromatography over silica gel and eluted with $\mathrm{CHCl}_{3}: \mathrm{MeOH}$ from 9:1 through 3:2. Two sub-fractions (Fr. 2a.1, Fr. 2a.2) were separated based on their TLC behaviour. Both were tested for contragestive activity where Fr. 2a.1 (major fraction, $250 \mathrm{mg}$ ) 
showed bioactivity. It was further purified by repeated column chromatography over silica gel to afford a pure compound having the required activity and subjected to ESI-MS (positive mode) and ${ }^{13} \mathrm{C}$ NMR.

\section{Antifertility studies}

Pilot study

A pilot study was conducted to screen the pregnancyterminating effects of puerarin. Cyclic female rats were paired with proven breeder males just before the end of the daily light cycle. The following morning, each female was examined for the presence of sperm in the vaginal lavage. The day the presence of sperm was observed was considered day 1 of gestation. Pregnant rats were allocated to four groups, each comprising six to eight animals. They were orally administered either puerarin at dose levels between 50 and $150 \mathrm{mg} / \mathrm{kg}$ or $1 \%$ gum acacia in distilled water (control) from D1 continuing through the entire pre-implantation phase (until D4) of gestation. The animals were laparotomised on D10 of pregnancy under light ether anaesthesia. The uteri were examined and photographed for the presence/absence of implantation sites. The dose level $(150 \mathrm{mg} / \mathrm{kg})$ at which no implantation site was present was considered as the effective dose for the 4-day treatment regimen. The ovaries were excised out and the numbers of functional $\mathrm{CL}$ were counted under dissecting microscope. Rate of implantation (\%) was calculated as the number of implantation sites per functional CL present in the ovary (Hiremath et al. 2000) and plotted against each concentration of puerarin to construct a dose-response curve.

\section{Optimisation of dose and duration}

With a view to optimising the MED regimen of puerarin for its antifertility effects, pregnant rats were treated with varying

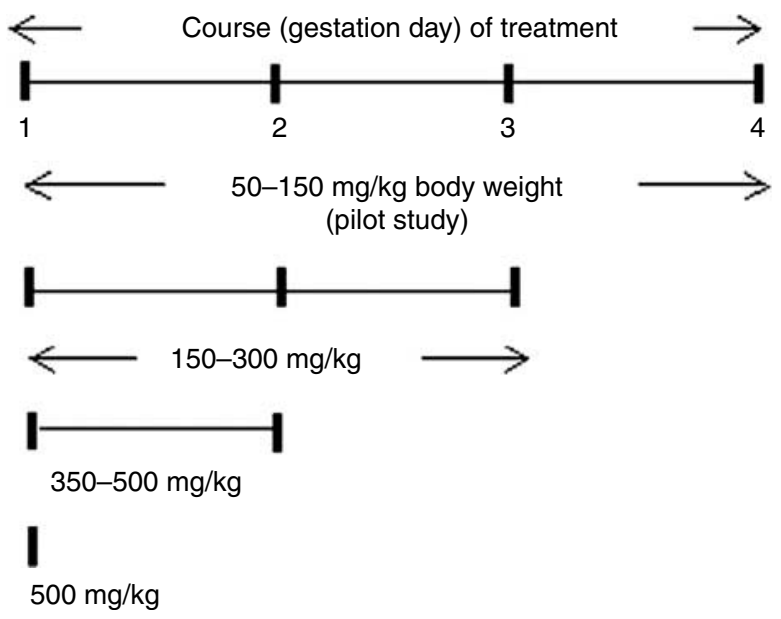

Figure 9 Schematic presentation of different treatment regimens. A pilot study was conducted involving oral administration of puerarin from D1 to D4 (D1 = presence of sperm in oestrous vaginal lavage) at different dose levels (50-150 mg/kg per day). Gradually, the duration of the treatment was reduced to a single day (D1) with progressive increase in dose to the maximum of $500 \mathrm{mg} / \mathrm{kg}$. doses of puerarin for different duration of the pre-implantation phase of gestation and observed for $100 \%$ antifertility effect (Fig. 9). The initial treatment regimen was $150 \mathrm{mg} / \mathrm{kg}$ per day for D1-D4. Step-wise the duration of treatment was reduced to single-day administration (D1), while the dosage was increased gradually over $150 \mathrm{mg} / \mathrm{kg}$ per day; total failure of pregnancy was considered as the target effect. The minimum dose and duration (300 mg/kg per day for D1-D2) that induced complete loss of pregnancy were considered as $\mathrm{MED}_{100}$; the subsequent investigations were performed with this dose-and-duration regimen.

\section{Mechanism of antifertility effects}

For the entire investigation, two sets of pregnant rats were maintained. The study group comprised rats treated orally with puerarin at $M E D_{100}$, which was $300 \mathrm{mg} / \mathrm{kg}$ per day administered for D1-D2; those treated with vehicle (1\% gum acacia) for the same duration formed the control group. Animals from control as well as treated groups (6-8/group) were subjected to each of the following investigations.

\section{Pontamine blue reaction}

On D5 at $1800 \mathrm{~h}$, the rats received injection of $0.3 \mathrm{ml}$ of $1 \%$ pontamine sky blue solution in $0.9 \%$ saline through tail vein under light ether anaesthesia. After $30 \mathrm{~min}$, all rats were killed. The uterine horns were dissected out; the numbers of blue spots produced in utero were taken as the presumptive sites of implantation (Nilsson \& Ljungkvist 1974) and photographed for documentation.

\section{Utero-ovarian histoarchitecture}

The uteri and ovaries were dissected out and cleansed from the extraneous tissues. The organs were fixed in Bouin's fixative (saturated aqueous picric acid $-75 \%$, formalin $-25 \%$ and glacial acetic acid $-5 \%$ ) and processed for routine staining with haematoxylin and eosin. The sections were examined and photographed under a light microscope (Carl Zeiss, Inc., Thornwood, NY, USA).

\section{Serum levels of $E_{2}$ and $P_{4}$ estimation}

Serum levels of $E_{2}$ were measured on each day between D2 and D5, while $\mathrm{P}_{4}$ was measured on D5 only. Blood was collected under anaesthesia at $0800 \mathrm{~h}$ of the corresponding day by cardiac puncture, serum was procured after centrifugation at $3000 \mathrm{~g}$ for $5 \mathrm{~min}$ and stored at $-20{ }^{\circ} \mathrm{C}$ until assayed. $\mathrm{E}_{2}$ was assayed using commercial RIA kit (E2-RIA-CT) purchased from Bio-Line S.A. -Rue Andre Fauchille 17-B-1150 Bruxelles-Belgium), while $\mathrm{P}_{4}$ levels were measured by automated chemiluminscence assay system (Immulite 2000; Diagnostics Product Corp., Los Angeles, CA, USA). The minimal detection limits were $0.08 \mathrm{ng} / \mathrm{ml}$ for $\mathrm{P}_{4}$ and $10 \mathrm{pg} / \mathrm{ml}$ for $\mathrm{E}_{2}$, and intra- and inter-assay coefficient of variations were $<10 \%$ for each assay. 


\section{Embryo retrieval}

D2-D4 embryos of both the control and treated rats were retrieved from the oviduct at $1400 \mathrm{~h}$ by flushing with $10 \%$ hyaluronidase in M2 medium, while D5 blastocysts were collected by flushing the uterine horns with M2 medium. Finally, the embryos were examined and photographed under phase contrast microscope (Zeiss Axiophot epifluorescent inverted microscope (Carl Zeiss, Inc.)).

\section{Indirect immunofluorescence of LIF, COX2 and VEGF}

For immunofluorescence assessment of LIF, COX2 and VEGF, uterine horns were fixed in $2-4 \%$ paraformaldehyde $(1-2 \mathrm{~h}$, $4{ }^{\circ} \mathrm{C}$ ) and embedded in paraffin. Sections were mounted on poly-L-lysine-coated slides and de-waxed in xylene. Nonspecific background staining was reduced by microwaving the sections for two 5-min intervals in $0.05 \mathrm{M}$ Tris- $\mathrm{HCl}(\mathrm{pH} 7.6)$, followed by cooling, and finally rinsing in PBS. The tissue was blocked in retrivergen solution as per instruction manual. Primary goat polyclonal LIF and COX2 (1:250 dilution in PBS) and rabbit polyclonal VEGF (1:200 dilution in PBS) antibodies were added and incubated overnight at $4{ }^{\circ} \mathrm{C}$. Primary antibodies were removed with $6 \times$ rinses in PBS. Negative controls were carried out using goat and rabbit IgG, as applicable. Uterine sections treated with LIF and COX2 antibodies were incubated in rabbit anti-goat IgG secondary antibody conjugated to FITC and anti-VEGF-treated sections were incubated with goat anti-rabbit IgG secondary antibody conjugated to FITC, for $90 \mathrm{~min}$ at room temperature in dark before $6 \times$ rinses in PBS and mounted in anti-fade Vectashield (Vector Laboratories, Inc., Burlingame, CA, USA) mounting medium (Cai et al. 2000). The sections were visualised and photographed (X200) with a Zeiss Axiophot epifluorescent microscope (Carl Zeiss, Inc.) equipped with a FITC filter set (Zeiss \#487909).

\section{Real-time PCR of ER $\alpha, E R \beta, P R B$ and PRAB}

Total RNA was extracted from uterine tissues by Trizol reagent (Invitrogen). RNA (5 $\mu$ g) was reverse transcribed to synthesise single-stranded cDNA using 'CDNA synthesis for PCR' kit from Fermentas (\#K1621; Glen Burnie, MD, USA). RNA was incubated at $42{ }^{\circ} \mathrm{C}$ for $50 \mathrm{~min}$ with $50 \mathrm{U}$ of superscript II Reverse Transcriptase in $20 \mu \mathrm{l}$ reaction volume containing $20 \mathrm{mM}$ Tris- $\mathrm{HCl}$ (pH 8.4), $50 \mathrm{mM} \mathrm{KCl}, 5 \mathrm{mM} \mathrm{MgCl} 2,10 \mathrm{mM}$ DTT, $0.5 \mathrm{mM}$ of each dNTP and $50 \mathrm{ng}$ random hexanucleotide primer. Rat-specific primers were designed and the sequences of primers used to amplify $E R \alpha, E R \beta, P R B$ and $P R A B$ mRNA were ER $\alpha$ : 5'-CCC AAG CTT GAT ACG AAA AGA CCG CC-3' (forward), 5'-CCG AAT TCC AAG TCC AAG CCT G-3' (reverse); ER $\beta$ : 5'-GAA TTC AAA GCT GCT GGG ATG GAG-3' (forward), 5'-CCCAAGCTTGTTGAGGAGGATCATG-3' (reverse); PRB: 5'-CAG ACC AAC CTG CAA CCA GAA-3' (forward), 5'-AGT CCT CAC CAA AAC CCT GGG-3' (reverse); and PR AB: 5'-CAG GCC GCG GTG CTCA A-3' (forward) 5'-GTG GGC TCT GGC TGG CTT CT-3' (reverse). The sequences of primers for GAPDH mRNA were 5' -TTG CCA TCA ATG ACC CCT TCA-3' (forward) and $5^{\prime}$-CGC CCC ACT TGA TTT TGG A-3' (reverse) (Murata et al. 2003).
Kinetic analyses were performed for each set of primers to determine the optimum number of cycles. The number of cycles was chosen from the linear portion of the kinetic plot. PCR conditions were optimised using gradient programme for each set of primers. The single-stranded cDNA was subjected to PCR using 'PCR reagent system' (Invitrogen Co.). Briefly, $2 \mu \mathrm{l}$ CDNA was amplified in a $50 \mu \mathrm{l}$ reaction volume containing $20 \mathrm{mM}$ Tris- $\mathrm{HCl}(\mathrm{pH} 8.4), 50 \mathrm{mM} \mathrm{KCl}, 1.5 \mathrm{mM} \mathrm{MgCl}_{2}, 200 \mu \mathrm{M}$ of dNTP each, $0.5 \mu \mathrm{g}$ of each primer and $1.25 \mathrm{U}$ of Taq DNA polymerase. The reaction was performed as follows; $94{ }^{\circ} \mathrm{C} / 30 \mathrm{~s}, 68^{\circ} \mathrm{C} / 45 \mathrm{~s}, 72^{\circ} \mathrm{C} / 45 \mathrm{~s}$ for ER $\alpha\left(35\right.$ cycles); $94{ }^{\circ} \mathrm{C} /$ $20 \mathrm{~s}, 63{ }^{\circ} \mathrm{C} / 10 \mathrm{~s}, 75^{\circ} \mathrm{C} / 70 \mathrm{~s}$ for $\operatorname{ER} \beta$ (27 cycles); $94^{\circ} \mathrm{C} / 30 \mathrm{~s}$, $58{ }^{\circ} \mathrm{C} / 45 \mathrm{~s}, 72{ }^{\circ} \mathrm{C} / 45 \mathrm{~s}$ for PRB (30 cycles); $94{ }^{\circ} \mathrm{C} / 30 \mathrm{~s}$, $57^{\circ} \mathrm{C} / 45 \mathrm{~s}, 72^{\circ} \mathrm{C} / 45 \mathrm{~s}$ for PRAB (35 cycles); and $94^{\circ} \mathrm{C} / 30 \mathrm{~s}$, $46^{\circ} \mathrm{C} / 45 \mathrm{~s}, 72{ }^{\circ} \mathrm{C} / 45 \mathrm{~s}$ for GAPDH (25 cycles) with a final extension at $72{ }^{\circ} \mathrm{C}$ for an additional $10 \mathrm{~min}$. The amount of expression was measured using Applied Biosystems 7500 realtime PCR (Applied Biosystems, Inc., University Park, IL 60484, USA). Summary of results derived from real-time PCR was first normalised to that of a housekeeping gene GAPDH and further calculated by the $2^{-\Delta \Delta C t}$ method and plotted as fold change. While comparing the expression levels between the days (D3-D5) within the group, expression of the corresponding mRNAs on D3 of the respective groups was arbitrarily assigned values 1 , but while comparing the mRNA levels between the control and study groups, the values are presented as fold changes with respect to the control mRNA levels for the respective days that were arbitrarily assigned values 1 .

\section{Statistical analysis}

Data were expressed as mean \pm s.E.M. The results were analysed by one tailed and paired two-tailed $t$-test, as applicable, using the GraphPad Prism 3.0 software (GraphPad software, Inc., San Diego, CA, USA). $P<0.05$ was considered significant.

\section{Declaration of interest}

The authors declare that there is no conflict of interest that could be perceived as prejudicing the impartiality of the research reported.

\section{Funding}

This research work was funded by Council of Scientific and Industrial Research, New Delhi, and Indian Council of Medical Research, New Delhi.

\section{Acknowledgements}

Indian Council of Medical Research, Department of Biotechnology and Council of Scientific and Industrial Research are gratefully acknowledged for providing Senior Research Fellowship to P Saha and Junior Research Fellowship to G Saraswat and S Banerjee respectively. 


\section{References}

Achache H \& Revel A 2006 Endometrial receptivity markers, the journey to successful embryo implantation. Human Reproduction Update 12 731-746. (doi:10.1093/humupd/dml004)

Ahrendt HJ, Adolf D \& Buhling KJ 2010 Advantages and challenges of oestrogen-free hormonal contraception. Current Medical Research and Opinion 26 1947-1955. (doi:10.1185/03007995.2010.493088)

Bitto A, Altavilla D, Bonaiuto A, Francesca P, Minutoli L, Stefano VD, Giuliani D, Guarini S, Arcoraci V \& Squadrito F 2009 Effects of aglycone genistein in a rat experimental model of postmenopausal metabolic syndrome. Journal of Endocrinology 200 367-376. (doi:10.1677/JOE-080206)

Boue ST, Wiese TE, Nehls S, Burow ME, Elliott S, Carter-Wientjes CH, Shih BY, McLachlan JA \& Cleveland TE 2003 Evaluation of the oestrogenic effects of legume extracts containing phyto-oestrogens. Journal of Agricultural and Food Chemistry 51 2193-2199. (doi:10.1021/ jf021114s)

Cai LQ, Cao YJ \& Duan EK 2000 Effects of leukaemia inhibitory factor on embryo implantation in the mouse. Cytokine 12 1676-1682. (doi:10. 1006/cyto.2000.0758)

Cassidy A 2003 Potential risks and benefits of phyto-oestrogen-rich diets. International Journal for Vitamin and Nutrition Research 73 120-126. (doi:10.1024/0300-9831.73.2.120)

Chakraborty I, Das SK, Wang J \& Dey SK 1996 Developmental expression of the cyclo-oxygenase- 1 and cyclo-oxygenase-2 genes in the periimplantation mouse uterus and their differential regulation by the blastocyst and ovarian steroids. Journal of Molecular Endocrinology $\mathbf{1 6}$ 107-122. (doi:10.1677/jme.0.0160107)

Chung HJ, Chung MJ, Houng SJ, Jeun J, Kweon DK, Choi CH, Park JT, Park KH \& Lee SJ 2009 Toxicological evaluation of the isoflavone puerarin and its glycosides. European Food Research and Technology 230 145-153. (doi:10.1007/s00217-009-1156-3)

Cravotto G, Boffa L, Genzini L \& Garella D 2010 Phytotherapeutics: an evaluation of the potential of 1000 plants. Journal of Clinical Pharmacy and Therapeutics 35 11-48. (doi:10.1111/j.1365-2710.2009. 01096.x)

Cullwell KR \& Curtis KM 2009 Use of contraceptive methods by women with current venous thrombosis on anticoagulant therapy: a systematic review. Contraception 80 337-345. (doi:10.1016/j.contraception.2009. 04.008)

Dey SK 1996 Implantation. In Reproductive Endocrinology, Surgery, and Technology, vol 1, pp 421-434. Eds EY Adashi, JA Rock \& Z Rosenwaks. Philadelphia: Lippincott-Raven.

Dey SK, Lim H, Das SK, Reese J, Paria BC, Daikoku T \& Wang H 2004 Molecular cues to implantation. Endocrine Reviews 25 341-373. (doi:10.1210/er.2003-0020)

Farrar SC, Yenari J \& Gherman RB 2003 Emergency contraception: a "fire extinguisher" for unintended pregnancies. Primary Care Update for OB/GYNS 10 284-287. (doi:10.1016/S1068-607X(03)00069-6)

Hamatani T, Daikoku T, Wang H, Matsumoto H, Carter MG \& Ko MSH 2004 Global gene expression analysis identifies molecular pathways distinguishing blastocyst dormancy and activation. PNAS 101 10326-10331. (doi:10.1073/pnas.0402597101)

Hiremath SP, Badami S, Hunasagatta SK \& Patil B 2000 Antifertility and hormonal properties of the flavones of Striga orobanchoides. European Journal of Pharmacology 391 193-197. (doi:10.1016/S0014-2999 (99)00723-2)

Hou X, Tan Y, Li M, Dey SK \& Das SK 2004 Canonical wnt signalling is critical to oestrogen-mediated uterine growth. Molecular Endocrinology 18 3035-3049. (doi:10.1210/me.2004-0259)

Hwang YP \& Jeong HG 2008 Mechanism of phyto-oestrogen puerarinmediated cytoprotection following oxidative injury: oestrogen receptordependent up-regulation of PI3K/Akt and HO-1. Toxicology and Applied Pharmacology 233 371-381. (doi:10.1016/j.taap.2008.09.006)

Jordan VC 2007 Chemoprevention of breast cancer with selective ooestrogen-receptor modulators. Nature Reviews. Cancer 7 46-53. (doi:10.1038/nrc2048)

Kahlenborn C, Stanford JB \& Larimore WL 2002 Postfertilization effect of hormonal emergency contraception. Annals of Pharmacotherapy $\mathbf{3 6}$ 465-470. (doi:10.1345/aph.1A344)
Keyes PL \& Wiltbank MC 1988 Endocrine regulation of the corpus luteum. Annual Review of Physiology 50 465-482. (doi:10.1146/annurev.ph.50. 030188.002341)

Kinjo JE, Furusawa JL, Baba J, Eakeshita T, Yamaski M \& Nohara T 1987 Studies on the constituents of Pueraria lobata III isoflavonoids and related compounds in the roots and the voluble stems. Chemical and Pharmacoceutical Bulletin 35 4846-4850. (doi:10.1248/cpb.35.4846)

Kuiper GG, Lemmen JG, Carlsson BO, Corton JC, Safe SH, van der Saag PT, van der Burg B \& Gustafsson J 1998 Interaction of ooestrogenic chemicals and phyto-oestrogens with oestrogen receptor $\beta$. Endocrinology 139 4252-4263. (doi:10.1210/en.139.10.4252)

Liu XJ, Jia Q, Wang CY \& Wang NL 2009 Study on absorption mechanism of puerarin and its nanoparticles across Caco-2 cell model. Journal of Chinese Medicinal Materials 32 1252-1255.

Ma W, Song H, Das SK, Paria BC \& Dey SK 2003 Oestrogen is a critical determinant that species the duration of the window of uterine receptivity for implantation. PNAS 100 2963-2968. (doi:10.1073/pnas. 0530162100)

Marino M \& Galluzzo P 2008 Oestrogen receptor $\beta$ mediates the protective effects of oestrogen in colon cancer. Cancer Therapy 6 149-162.

Matsumoto H, Ma W, Daikoku T, Zhao X, Paria BC, Das SK, Trzaskos JM \& Dey SK 2002 Cyclooxygenase-2 differentially directs uterine angiogenesis during implantation in mice. Journal of Biological Chemistry 277 29260-29267. (doi:10.1074/jbc.M203996200)

McCracken JA, Custer EE \& Lamsa JC 1999 Luteolysis: a neuroendocrinemediated event. Physiological Reviews 79 263-323.

Mendez MN 2002 Emergency contraception: a review of current oral options. Western Journal of Medicine 176 188-191. (doi:10.1136/ewjm. 176.3.188)

Mersereau JE, Levy N, Staub RE, Baggett S, Zogric T, Chow S, Ricke WA, Tagliaferri M, Cohen I, Bjeldanes LF et al. 2008 Liquiritigenin is a plantderived highly selective oestrogen receptor $\beta$ agonist. Molecular and Cellular Endocrinology 283 49-57. (doi:10.1016/j.mce.2007.11.020)

Minorics R, Ducza E, Marki A, Paldy E \& Falkay G 2004 Investigation of oestrogen receptor $\alpha$ and $\beta$ mRNA expression in the pregnant rat uterus. Molecular Reproduction and Development 68 463-468. (doi:10.1002/ $\operatorname{mrd}$.20106)

Misrahi M, Loosfelt H, Atger M, Meriel C, Zerah V, Dessen P \& Milgrom E 1988 Organisation of the entite rabbit progesterone receptor mRNA and of the promoter and $5^{\prime}$ flanking region of the gene. Nucleic Acids Research 16 5459-5472. (doi:10.1093/nar/16.12.5459)

Murata T \& Higuchi T 2003 Progesterone receptor mRNA levels during pregnancy, labor, lactation and the estrous cycle in the rat uterus. Journal of Reproduction and Development 49 425-432. (doi:10.1262/ jrd.49.425)

Murata T, Narita K, Honda K, Matsukawa S \& Higuchi T 2003 Differential regulation of oestrogen receptor alpha and beta $m R N A s$ in the rat uterus during pregnancy and labor: possible involvement of oestrogen receptors in oxytocin receptor regulation. Endocrine Journal 50 579-587. (doi:10. 1507/endocrj.50.579)

Nilsson J \& Ljungkvist I 1974 Blastocyst-endometrial contact and pontamine blue reaction during normal implantation. Journal of Endocrinology 60 149-154. (doi:10.1677/joe.0.0600149)

Prata N 2009 Making family planning accessible in resource-poor settings. Philosophical Transactions of the Royal Society of London. Series B, Biological Sciences 364 3093-3099. (doi:10.1098/rstb.2009.0172)

Psychoyos A 1973 Hormonal control of ovoimplantation. Vitamins and Hormones 31 201-256. (doi:10.1016/S0083-6729(08)60999-1)

Psychoyos A 1984 Uterine sensitivity for blastocyst implantation. Journal of Biosciences 6 7-10. (doi:10.1007/BF02716711)

Psychoyos A, Nikas G \& Gravanis A 1995 The role of prostaglandins in blastocyst implantation. Human Reproduction 10 30-42. (doi:10.1093/ humrep/10.suppl_2.30)

Sahlin L, Masironi B, Akerberg S \& Eriksson H 2006 Tissue- and hormonedependent progesterone receptor distribution in the rat uterus. Reproductive Biology and Endocrinology 4 1-11. (doi:10.1186/14777827-4-47)

Sander PM, Raymond EG \& Weaver MA 2009 Emergency contraceptive use as a marker of future risky sex, pregnancy and sexually transmitted infection. American Journal of Obstetrics and Gynecology 201 146.e1-146.e6. (doi:10.1016/j.ajog.2009.05.015) 
Sengupta J, Paria BC \& Manchanda SK 1983 Steroid hormones and embryo development in ovariectomized hamsters. Journal of Reproduction and Fertility 67 369-372. (doi:10.1530/jrf.0.0670369)

Shukla S 1996 Post-coital contraceptive action of Pueraria tuberosa DC. extract in rats. Phytotherapy Research 10 95-99. (doi:10.1002/ (SICl)1099-1573(199603)10:2 <95::AID-PTR699> 3.0.CO;2-5)

Shukla S \& Mathur R 2002 Purareia tuberosa DC: contraceptive efficacy and toxicological profile. In Pueraria: the Genus Pueraria, 1st edn, pp 85-97. Eds Keung MW. New York: Taylor and Francis, Inc.

Simon C, Domınguez F, Valbuena D \& Pellicer A 2003 The role of oestrogen in uterine receptivity and blastocyst implantation. Trends in Endocrinology and Metabolism 14 197-199. (doi:10.1016/S10432760(03)00084-5)

Song H, Lim H, Das SK, Paria BC \& Dey SK 2000 Dysregulation of EGF family of growth factors and COX-2 in the uterus during the preattachment and attachment reactions of the blastocyst with the luminal epithelium correlates with implantation failure in LIF-deficient mice. Molecular Endocrinology 14 1147-1161. (doi:10.1210/me.14.8. 1147)

Sylvestre M, Pichette A, Longtin A, Nagau F \& Legault J 2006 Essential oil analysis and anticancer activity of leaf essential oil of Croton flavens L. from Guadeloupe. Journal of Ethnopharmacology 103 99-102. (doi:10. 1016/j.jep.2005.07.011)

Tabibzadeh S 1998 Molecular control of the implantation window. Human Reproduction Update 4 465-471. (doi:10.1093/humupd/4.5.465)

Terkel J 1988 Neuroendocrine processes in the establishment of pregnancy and pseudopregnancy in rats. Psychoneuroendocrinology 13 5-28. (doi:10.1016/0306-4530(88)90004-2)
Wang H \& Dey SK 2006 Roadmap to embryo implantation: clues from mouse models. Nature Genetics 7 185-199. (doi:10.1038/nrg1808)

Ware CB, Horowitz MC, Renshaw BR, Hunt JS, Liggit D, Koblar SA, Gliniak BC, McKena HJ, Papayannopoulou T, Thoma B et al. 1995 Targeted disruption of the low-affinity leukemia inhibitory factor receptor gene causes placental, skeletal, neural and metabolic defects and results in perinatal death. Development 121 1283-1299.

White CA, Zhang JG, Salamonsen LA, Baca M, Fairlie WD \& Metcalf D 2007 Blocking LIF action in the uterus by using a PEGylated antagonist prevents implantation: a nonhormonal contraceptive strategy. PNAS 104 19357-19362. (doi:10.1073/pnas.0710110104)

Wu H, Lu C, Zhou A, Min Z \& Zhang Y 2009 Enhanced oral bioavailability of puerarin using microemulsion vehicle. Drug Development and Industrial Pharmacy 35 138-144. (doi:10.1080/03639040801973495)

Wuttke W, Jarry H \& Seidlov $\boldsymbol{\alpha}$-Wuttke D 2010 Definition, classification and mechanism of action of endocrine disrupting chemicals. Hormones 9 9-15.

Zheng G, Zhang X, Zheng J, Meng Q \& Zheng D 2002 Oestrogen-like effects of puerarin and total isoflavones from Pueraria lobata. Journal of Chinese Medicinal Materials 25 566-568.

Received 6 November 2011

First decision 12 December 2011

Revised manuscript received 10 August 2012

Accepted 23 August 2012 